\title{
Entre prosa e poesia: lições de uma oficina poética com Carlito Azevedo
}

Túlio D’El-Rey*

Em Incubadoras literárias: o lugar do contemporâneo no campo da literatura brasileira (2014), Milton Colonetti destaca a importância das oficinas como instâncias úteis para a compreensão do contexto literário da contemporaneidade. Fenômeno emergente no Brasil, a realização de cursos de escrita criativa tem se mostrado relevante para o fomento de uma sociabilidade e para o compartilhamento de estratégias escriturais capazes de contribuir para a inserção de autores aspirantes no meio. Somada à emergência das oficinas literárias, outra marca do momento atual é a popularização e consolidação da internet também como terreno da literatura. Outrora circunscrito a uma localização geograficamente delimitada, o campo literário contemporâneo adquiriu nova amplitude a partir do ciberespaço. Assim, conforme aponta Guilherme Côrrea de Freitas em Vida literária virtual: internet e relações literárias no Brasil, "a presença virtual de escritores através de blogs e publicações eletrônicas estende para a rede o debate cultural e cria um novo ambiente para a vida literária" $(2005,21)$.

A partir desse contexto, torna-se coerente a ideia de explorar o espaço virtual para a realização de cursos de escrita criativa. No Brasil, uma das iniciativas nessa direção foi realizada pelo Portal

\footnotetext{
${ }^{*}$ Doutorando em Literatura e Cultura na Universidade Federal da Bahia (UFBA).
} 
Literal, projeto sob curadoria da crítica Heloisa Buarque de Hollanda, que, além do conteúdo típico das revistas culturais - artigos, críticas, ensaios, resenhas, entrevistas etc. -, dedicava uma seção específica para a promoção de oficinas literárias virtuais. Durante a existência do portal, mantido no ar entre 2002 e 2014, vários cursos (pagos e gratuitos) foram oferecidos sob a tutela de figuras relevantes do campo literário contemporâneo, como José Castello, que ministrou uma oficina de contos; Sérgio Alcides, responsável por uma oficina de tradução de poesia; e Carlito Azevedo, coordenador de uma oficina poética. Comemorando seus dez anos de existência em 2012, foi publicada parte do conteúdo do Portal Literal numa revista homônima, cujos dois primeiros números trouxeram, na íntegra, o curso de José Castello e o curso de Carlito Azevedo.

\section{Acesso à Oficina Poética}

Entre dezembro de 2005 e maio de 2006, o Portal Literal promoveu e hospedou uma oficina com o poeta Carlito Azevedo, posteriormente republicada em sua totalidade na revista Literal $\mathrm{n}^{\circ}$ 2. A partir do conteúdo da referida oficina, buscarei aqui discutir algumas questões pertinentes à poesia contemporânea e, por conseguinte, à produção do próprio Carlito Azevedo, com destaque para a relação cada vez mais presente entre prosa e poesia.

Dividida em dez aulas, a oficina de criação poética apresentou algumas das principais questões que envolvem a produção de poesia na contemporaneidade e funcionam como uma interessante bússola para boa parte das referências estéticas que balizam a poética atual. Mais do que trazer estratégias que sirvam para dar gatilho à criatividade ou "tornar alguém poeta", o que Carlito busca é apresentar autores e poemas com os quais dialoga e que, 
de certa maneira, comporiam uma espécie de antologia para compreender os aspectos em discussão. Por isso o poeta faz questão de advertir seus leitores sobre quaisquer concepções claramente hierarquizantes, ainda que vários nomes apresentados sejam considerados canônicos, como Jorge Luis Borges, Charles Baudelaire, João Cabral de Melo Neto e Carlos Drummond de Andrade: “e não importam aqui hierarquizações do tipo 'quem é mais importante que quem'... Deixemos essa ociosa tarefa para os que acham alguma graça em hierarquizar coisas que podem muito bem ser vistas de uma perspectiva não hierárquica..." (Azevedo: 2012, 16). Essa postura também está alinhada à fuga de uma concepção sacralizante da poesia, marcada, entre outras coisas, por uma caminhada rumo à prosa, conforme veremos mais adiante.

Para referendar a quebra de uma ideia preconcebida de hierarquia, Carlito Azevedo parafraseia um texto de T. S. Eliot a respeito do amor à poesia. Para Eliot, amaria realmente a arte poética aquele que desgostasse de ao menos um poeta considerado maior, amado por todos, e que, em contrapartida, mantivesse carinho por um poeta considerado menor e não tão amado pelos outros. Desse modo, não haveria razão para incômodo dos alunos ao verem "em absoluta convivência democrática nomes como Ezra Pound e Charles, Mallarmé e Heitor Ferraz, João Cabral e Adília Lopes... O coração de quem ama poesia tem lugar para todos..." (Azevedo: 2012, 17).

\section{Escolhas afetivas e frequentação}

Ao advogar por uma seleção supostamente baseada na afetividade, Carlito Azevedo demonstra que os autores apresentados ao longo da oficina são frutos de escolhas afetivas, como preconiza Luciana di Leone, em Poesia e escolhas afetivas: edição e escrita na poesia 
contemporânea (2014). Esta afetividade não se fundaria apenas pelo viés do amor ou pela escolha do coração, mas também pelo potencial dialógico, da ordem de uma afecção espinoziana, enquanto algo que afeta promovendo a eclosão de uma determinada potência. Ou seja, cada um dos textos e autores apresentados teria como principal função dialogar com os leitores, contato que viria a promover uma dada criação artística, algo que pode ser percebido como gatilho na própria produção poética de Carlito Azevedo. Será, portanto, o caráter dialógico da poesia, cuja linguagem, de acordo com Silviano Santiago, existiria "em estado de constante travessia para o Outro" (2002, 61), o principal instrumento de criação apresentado na oficina poética em questão.

Visto de outro modo, esse componente dialógico pode ser associado à ideia de frequentação, tal qual exposto por Susana Scramim a respeito da construção autoral de Carlito Azevedo. De acordo com ela, a poética de Carlito pode ser entendida a partir de seu diálogo com outros autores, uma poesia "à maneira de", processo que deve ser entendido como "uma ação, uma posição frente aos textos e à literatura" (apud Prigol: 2012, 133). Por essa visão, seria possível compreender a produção poética de Carlito Azevedo como fruto da recorrente frequentação de outros textos, autores e obras.

Diante disso, é possível inferir que, para que a afecção ocorra, se faz necessário que o poeta frequente outros poetas e, consequentemente, suas produções. Tal mecanismo de criação se reproduziria no modus operandi da própria oficina poética, entendida por Valter Prigol como "uma oficina de frequentação porque, como cada uma [das lições] se organiza a partir de um tema, este tema serve para o autor produzir uma 'antologia' de poemas sobre ele e comentá-los, convidando o leitor a frequentá-los" $(2012,135)$. 
O mecanismo operatório pode ser demonstrado desde a primeira aula, na qual os alunos são apresentados ao chamado "método Vila-Matas". De acordo com Carlito Azevedo, o escritor espanhol Enrique Vila-Matas, cuja notoriedade advém principalmente da escrita de crônicas e romances, teria entrado para a literatura através de um método próximo à frequentação. Ainda durante o colégio, apaixonado por uma garota, o romancista teria se apropriado da lírica como forma de conquista. Porém, inseguro sobre suas habilidades poéticas, resolveu copiar um poema inteiro do poeta espanhol Luis Cernuda, ao qual acrescentou um verso autoral. Incentivado pelos elogios recebidos, afinal um dos versos era mesmo seu, Vila-Matas teria aumentado gradativamente sua presença autoral nos poemas seguintes, até enviar apenas textos completamente escritos por si. Familiarizados com o "método Vila-Matas" por meio dessa anedota, os leitores/participantes da oficina são, então, convidados por Carlito Azevedo a reproduzir o procedimento como atividade final do módulo:

Pegue um poema de algum poeta de sua preferência e insira nele uma estrofe inteira de sua autoria... depois, pegue sua estrofe e faça seu próprio poema... podemos considerar que os poetas nascem um dos outros, e que do casulo de um sai a borboleta de outro... (Azevedo: 2012, 19).

Ao solicitar a inserção de um texto próprio em um poema já conhecido, o exercício em questão incentiva a realização efetiva de uma frequentação motivada pelo diálogo afetivo. Tem-se então uma dupla intervenção: a do leitor que se torna produtor em um texto que admira e a do texto admirado em seu leitor, que produz 
um novo texto a partir do anterior. Tal proposta pode ser entendida também como um ato de produção desses textos bastante contemporâneo, como indica Agamben, em O que é contemporâneo? e outros ensaios (2009), ao trazê-los para o presente e atualizá-los, imprimindo novas marcas. É o antigo, com a presença de algo novo, se (re)fazendo no agora.

Em associação com ao que Luciana di Leone alude quando fala das escolhas afetivas, o exercício da frequentação, apontado por Susana Scramin, também pode ser identificado na prática coletiva de alguns poetas que surgiram na Argentina e no Brasil durante as décadas de 1990 e 2000, cuja produção é bastante marcada pela interseção de vozes entre os pares. Sem possuir bandeiras ou programas definidos, esses poetas manteriam uma noção de comunidade - no rastro do que Agamben teoriza em A comunidade que vem (2002) - que se pautaria pela abolição de um suposto elo comum para abarcar justamente as diferenças. A partir disso, não havendo um projeto claro, ao menos nos moldes do que estaria presente nas vanguardas históricas, o principal liame seria a busca de um fazer poético mediado pela coletividade. Um exemplo interessante dessa relação entre os pares é o poema "O que pensa o contacto (vozes do 23)", presente no livro Jet-lag, de Aníbal Cristobo (2002), cujos versos na verdade são de autoria de Carlito Azevedo. Para Luciana di Leone, este texto evidenciaria os sintomas

de um modo de editar, escrever e ler poesia que ganha força na produção poética do Brasil e da Argentina das últimas décadas. Modo de editar, escrever e ler que investe no que a edição, a escrita e a leitura têm de prática "coletiva", na qual o autor se dissemina, deixando de ser garantia do sentido 
e dono do escrito, deixando de apelar a uma "voz própria”, e articulando diferentes tempos, espaços e vozes de forma não hierárquica nem identificatória $(2014,22)$.

No entanto, para tornar-se possível, essa prática coletiva dependeria da existência de um espaço propício, como teria sido, para Luciana di Leone, a 7Letras, cujo catálogo possui uma quantidade substancial de publicações consideradas relevantes para o cenário da poesia brasileira contemporânea. No microcosmo ao redor da editora seria possível identificar uma sociabilidade e uma convivência bastante propícias para a emergência de novas vozes na poesia nacional. Segundo Marília Garcia, uma das autoras que apareceram nesse cenário, "o ambiente da editora naquele momento possibilitava um diálogo intenso entre os autores, editores, tradutores e pessoas próximas à poesia" (apud Leone: 2014, 93), o que incluía, ainda que informalmente, "uma espécie de oficina poética, no sentido mais experimental da palavra, com trocas de textos, traduções, impressões e leituras" (2014, 93). Desse modo, é possível perceber uma associação direta entre o convívio no ambiente da editora com uma proposta de oficina poética que tem em seu cerne a ideia de produzir coletivamente, em um diálogo incessante que gira em torno das impressões a partir de leituras.

Analogamente, tal dinâmica estaria contida no funcionamento da Oficina Poética de Carlito Azevedo, cujo propósito, conforme comentado anteriormente, seria promover a criação por meio do contato, ou melhor, da frequentação a determinadas antologias para a discussão de questões poéticas contemporâneas. Para que esse formato seja efetivo, é necessário o exercício de uma leitura interessada, entendida como atributo considerado essencial para a formação de qualquer autor, tal qual demonstra Luiz Antonio de Assis Brasil: 
O escritor lê, como todos leem, mas a diferença é que o escritor lê com a intenção de saber. A qualidade da leitura é, portanto, o traço que transformará alguém em escritor. Essa qualidade é adquirida, seja por uma espontânea disposição intelectual, seja por estímulo de alguém: a história da literatura está cheia de exemplos de escritores que orientaram as leituras dos iniciantes (apud Reis: 2014, s.p.).

Na Oficina Poética, Carlito Azevedo atuaria de modo análogo ao referido por Brasil, visando estimular e orientar a leitura de outros escritores. Tal postura serviria, além da relação com uma frequentação poética e a proposição de um diálogo afetivo, como uma via potencial de inserção, uma vez que, segundo Pierre Bourdieu, "no campo artístico [...] não há lugar para aqueles que ignoram a história do campo e tudo que ela engendrou" (1996, 275). Nesse sentido, a oficina é também um mecanismo por meio do qual determinados conhecimentos sobre a tradição são transmitidos, permitindo que escritores em potencial possam compreender melhor as estratégias que mediariam a inserção na literatura.

\section{Limites: entre prosa e poesia}

Como dito anteriormente, a Oficina Poética aqui observada teria como principal foco discutir e apresentar questões próprias da criação de poesia na contemporaneidade. Desse modo, vale destacar um dos temas abordados, cuja presença não apenas se mostra na discussão contemporânea do fazer poético, mas também compõe papel importante dentro da obra de Carlito Azevedo: a relação entre prosa e poesia.

Reconhecido, a partir do início dos anos 1990, por compor versos "sofisticadíssimos e difíceis em seu diálogo com a montagem 
cinematográfica eisenteiniana” (Ornellas: 2013, 86), Carlito optou, em seus livros mais recentes, "por escrever vários poemas em prosa narrativa, recheados em personagens reais ou imaginários, em evidente clave alegórica" (2013, 86). A mudança de postura, entendida por Sandro Ornellas no contexto de uma reterritorialização promovida pela influência da internet na produção poética atual - cujo desdobramento, em Carlito Azevedo, se faz ainda mais perceptível com Livro das postagens (2016), no qual é possível perceber desde poemas até postagens e conversas no Facebook -, também seria o resultado de uma relação mais aproximada do poeta com as discussões da poética francesa contemporânea. Segundo Maria José Lemos (2012), Carlito teria estreitado esse diálogo com a França a partir de seu trabalho como tradutor e editor da revista Inimigo Rumor, na qual foi responsável por publicar vários ensaios e poemas de autores franceses, entre eles figuras como Jean-Marie Gleize e Pierre Alféri, marcadamente interessados nos limites entre prosa e poesia.

Para Marcos Siscar, em "Figuras de prosa: a ideia da 'prosa' como questão de poesia", a discussão em torno do prosaísmo dentro do poético "constitui uma das questões fundamentais, se não a mais importante, da reflexão que a poesia moderna vem fazendo sobre si mesma" (2015, 31). Diante disso, é relevante salientar como a diferença em relação à prosa tem servido como base para a definição do que seria poesia e o surgimento de um mal-estar "cada vez que a poesia [...] se sente concernida pela prosa (lhe concede espaço, caminha na sua direção, perdendo a clareza ou a necessidade de suas fronteiras e de suas tarefas)" (2015, 31). Tal desconforto, para Siscar, constituiria o chamado "discurso da crise da poesia" (2015, 31), que nesse âmbito se colocaria como "negociação contínua (sujeita a vários tons: pensativo, 
resistente, autonomista, hibridizante) que a poesia realiza com a prosa, ou seja, com [...] a questão dos seus limites" (2015, 31; grifo do autor).

Um dos pensadores a respeito dessa fronteira difusa é o filósofo italiano Giorgio Agamben, cujo ensaio "O fim do poema" alude à tese da definição da possibilidade do enjambement como

o único critério que permite distinguir a poesia da prosa. Pois o que é o enjambement senão a oposição entre um limite métrico e um limite sintático, uma pausa prosódica e uma pausa semântica? Portanto, será chamado poético o discurso no qual essa oposição for, pelo menos virtualmente, possível, e prosaico aquele no qual não puder haver lugar para ela $(2002,142)$.

A partir dessa definição, Agamben discute o que seria então o fim do poema, uma vez que "no último verso de um poema o enjambement não é pensável" (2002,144). Assim, "se o verso se define precisamente através da possibilidade do enjambement, segue-se daí que o último verso de um poema não é um verso. Quer dizer isto que o último verso se transfunde em prosa?" $(2002,145)$. Tem-se aí uma potente ambiguidade entre o sentido de fim como a última parte, aquela que conclui o texto, e o fim como a finitude da própria poesia que teria a prosa em seu horizonte.

Em sua Oficina Poética, Carlito Azevedo considera que o tema se colocaria basicamente a partir das seguintes questões: "O poema para ser poema precisa do verso? O poema depende do verso? É refém do verso? Há poema fora do verso?” (Azevedo: 2012, 31). Para respondê-las, o autor se utiliza da tradição, do "aval de alguns dos mais incontestáveis poetas do século XIX" (2012, 31), como 
Baudelaire, Arthur Rimbaud e Stéphane Mallarmé, e tantos outros ao longo do século XX, como "Francis Ponge, Drummond, Lautréamont, Manuel Bandeira, João Cabral, Octavio Paz, Jorge Luis Borges, Pablo Neruda, César Vallejo" (2012, 31). Amparado pelo cânone, o poeta apresenta uma definição breve de poema em prosa que serviria de resposta para os questionamentos apresentados: "O poema em prosa 'canônico' não é aquele escrito em 'linguagem prosaica'. É aquele que, independentemente da linguagem utilizada, abandona o verso, e segue de uma à outra margem da página linearmente... sem quebras, como na prosa" (2012, 34).

Longe de buscar um apaziguamento, o conceito trazido por Carlito Azevedo serve propositalmente como um complicador, à medida que o leitor é defrontado com pequenas narrativas - ou poemas em prosa - escritas por reconhecidos prosadores, como Franz Kafka, Max Jacob e Caio Fernando Abreu. Diante desses textos, ressurgiria o impasse a respeito do gênero, o que tornaria inviável o enquadramento como prosa ou poesia. Ante a impossibilidade de uma clara separação, o poeta sugere o caminho da hibridez.

Porque se há romances que são evidentemente romances, e se há poemas que são evidentemente poemas, há também "trabalhos" que ousam penetrar numa região híbrida, agir como espiões infiltrados em território alheio... roubando dali o que bem lhe interessar. Para esses textos, a mistura e a hibridez são mais valiosas que a obediência estrita aos cânones... (Azevedo: 2012, 35).

Tal engajamento, no contexto da Oficina Poética, é defendido a partir do livro Pequenos poemas em prosa, de Charles Baudelaire, 
cuja guinada rumo à prosa se relacionaria com a busca de libertar amarras, rompendo com as formas tradicionais e adicionando novas formas à tradição. Carlito Azevedo lembra que àquela altura já havia a noção de verso livre, sobretudo com Walt Whitman e Arthur Rimbaud, o que poderia ter sido considerado por Baudelaire como uma espécie de paliativo ou truque para a sobrevivência do verso em novos tempos. Porém, para o autor de As flores do mal, não caberiam paliativos. Conclui Carlito: "Se é para deixar o verso, que seja para penetrar de vez, sem pudores, no território proibido da prosa" (2012, 38).

Pensar a respeito da motivação de Baudelaire para abraçar a prosa em sua época faz-se relevante como uma reflexão rentável para a contemporaneidade, uma vez que, segundo Marcos Siscar, discutir a questão da prosa dentro da poesia seria também dar atenção a uma necessária discussão contemporânea que, retomando o que já foi colocado por Carlito Azevedo, estaria discutindo os limites e margens da poesia. Para Siscar, toda crise gerada pela indefinição dos gêneros contribuiria para trazer à tona "pontos sensíveis que ajudam a reconhecer os desafios estéticos e culturais do contemporâneo" (2015, 33). Por essa via, o destaque caberia a outro poeta francês, Francis Ponge, cuja relação com a prosa assumiria um sentido "autocrítico", visto que sua "exploração dos limites da poesia permite uma objetivação que pretende superar não apenas as convenções do gênero, mas também o caráter organizador do sujeito lírico e, portanto, a própria oposição entre sujeito e objeto" (2015, 33).

Na Oficina Poética, Ponge é trazido por Carlito Azevedo justamente no momento em que a questão do sujeito lírico entra em pauta. Diante do bombardeio promovido pela psicanálise, filosofia e linguística, a poesia teria perdido a função de refúgio e socorro do 
sujeito. Desse modo, a aparição do "eu" poético seria sempre sob a forma da contestação: ora retorcido, ora morto, ora inviável, ora zumbi, ora fantasmagórico etc. Ou seja, sempre como resíduo, abandonando o papel dominante e limitado "a ser mais uma coisa entre coisas, um EU que duvida de si" (Azevedo: 2012, 25). Por essa via, uma das soluções encontradas seria abdicar do sujeito poético para se debruçar sobre as coisas, caminho tomado por Francis Ponge em Le Parti pris des choses (1942), que se poderia traduzir por "o partido das coisas", ou "tomando o partido das coisas". Tal qual esclarece Marcos Siscar, o poeta em questão produz uma poética que foge da lógica do sujeito como centro de interesse do poema.

No âmbito da fronteira com a prosa, Ponge é destacado como um poeta dotado de uma clara vontade de buscar a superação dos limites poéticos, fator que contribuiria para sua pulsão em direção à prosa. Para Jean-Marie Gleize, essa postura iria mais além, dado que ele seria "um poeta para quem a poesia já não existia, [...] [que] falava de 'poesia batida achatada em prosa' ou de 'prosa achatada"' (apud Siscar: 2015, 33). Por isso Ponge seria considerado o ponto de partida para a compreensão do que vem sendo produzido atualmente pela poética francesa da "literalidade", cujo principal interesse estaria em romper com uma dada visão autônoma e sacralizada da linguagem poética, o que implicaria, entre outras coisas, a busca da prosa. Nesse sentido, Pierre Alféri considera que o caminho rumo à prosa é a busca “do 'ideal baixo' da poesia, é descolar-se da mistificação da altura e do sublime, atribuída à tradição poética" (apud Siscar: 2015, 36). Tal compreensão viria pela ideia de que, na contemporaneidade, a poesia já não dá conta de se comunicar com seu próprio tempo o que se evidencia na proposta de Baudelaire, segundo a leitura de Carlito Azevedo. Diante desse abalo, Jean-Marie Gleize considera 
haver a necessidade de pensar em uma nova denominação, a partir dessa virada rumo à prosa, que estaria contida no termo "pós-poesia", definido como "aquilo que sobrevém à poesia na direção da prosa, da 'prosa em prosa"' (apud Siscar: 2015, 36).

Posto isso, ao pensar o contexto atual, em que prosa e poesia se hibridizam e a busca de uma está no horizonte da outra, a conclusão da Oficina Poética de Carlito Azevedo se aproxima do fechamento do ensaio "O fim do poema", de Giorgio Agamben. Se para o filósofo italiano, parafraseando Wittgenstein, "a poesia deve-se apenas propriamente filosofá-la" (Agamben: 2002, 148), para o poeta brasileiro a lição seria: "Leia os filósofos e faça poemas" (Azevedo: 2012, 87). 


\section{Referências}

AGAMBEN, Giorgio. "O fim do poema". Tradução de Sérgio Alcides. Cacto, $\mathrm{n}^{\circ} 1,2002$, pp. 142-9.

. A comunidade que vem. Tradução de Cláudio Oliveira. Belo Horizonte: Autêntica, 2002.

. “O que é o contemporâneo?". In: O queécontemporâneo? E outros ensaios. Tradução de Vinícius Nicastro Honesko. Chapecó: Argos, 2009, pp. 55-73.

AZEVEDO, Carlito. “Oficina Poética”. Revista Literal, n 2, nov. 2012, pp. 12-87. Disponível em: https://issuu.com/revista_portal_literal_2012/docs/revista_literal_n._02. Acesso em 23 de abril de 2017. . Livro das postagens. Rio de Janeiro: 7Letras, 2016.

BOURDIEU, Pierre. As regras da arte: gênese e estrutura do campo literário. Tradução de Maria Lucia Machado. São Paulo: Companhia das Letras, 1996.

COLONETTI, Milton. Incubadoras literárias: um problema de história editorial. Tese de doutorado defendida na Faculdade de Letras da Universidade Federal do Rio Grande do Sul (UFRGS). Porto Alegre, 2014. Disponível em: http://tede2.pucrs.br/ tede2/bitstream/tede/2188/1/462832.pdf. Acesso em 23 de abril de 2017.

FREITAS, Guilherme Côrrea de. Vida literária virtual: internet $e$ relações literárias no Brasil. Trabalho de conclusão de curso da Escola de Comunicação da Universidade Federal do Rio de Janeiro (UFRJ). Rio de Janeiro, 2005. Disponível em: http://pantheon.ufrj.br/bitstream/11422/1356/1/GFreitas. pdf. Acesso em 23 de abril de 2017. 
LEMOS, Maria José Cardoso. "Carlito Azevedo e Marcos Siscar: entre prosa e poesia, crise e saídas”. In: SCRAMIM, Susana; LINK, Daniel \& MORICONI, Italo (orgs.). Teoria, poesia, crítica. Rio de Janeiro: 7Letras, 2012, pp. 231-58. Disponível em: https://www.academia.edu/4600782/Carlito_Azevedo_e_Marcos_Siscar_entre_prosa_e_poesia_crise_e_ sa\%C3\%ADdas. Acesso em 23 de abril de 2017.

LEONE, Luciana di. Poesia e escolhas afetivas: edição e escrita na poesia contemporânea. Rio de Janeiro: Rocco, 2014.

ORNELLAS, Sandro. "POESIA.NET: quatro apontamentos sobre literatura e internet". Percursos - Revista Eletrônica dos Cursos de Licenciatura da UNIJORGE, $\mathrm{n}^{0}$ 1, jan-jun/2013, pp. 80-8. Disponível em: http://revistas.unijorge.edu.br/percursos/ pdf/2013_SandroOrnellas.pdf. Acesso em 23 de abril de 2017. PONGE, Francis. Le Parti pris des choses [1942]. Paris: Folioplus, 2009.

PRIGOL, Valdir. "Poesia, crítica e mediação". Revista Letras, no 86, jul-dez/2012, pp. 131-40. Disponível em: http://revistas. ufpr.br/letras/article/view/26891/19909. Acesso em 23 de abril de 2017.

REIS, Vilto. "Entrevista com Luiz Antonio de Assis Brasil: o maior formador de escritores do país”. Homo Literatus, jan/2014. Disponível em: http://homoliteratus.com/entrevista-comluiz-antonio-de-assis-brasil-o-maior-formador-de-escritores-do-pais/. Acesso em 23 de abril de 2017.

SANTIAGO, Silviano. "Singular e anônimo". In: . Nas malhas das letras. Rio de Janeiro: Rocco, 2002, pp. 61-71.

SISCAR, Marcos. "Figuras de prosa: a ideia da 'prosa' como questão de poesia”. In: PUCHEU, Alberto \& SCRAMIM, Susana (orgs.). 
O duplo estado da poesia: modernidade e contemporaneidade. São Paulo: Iluminuras, 2015, pp. 29-40. 


\section{Resumo}

Entre dezembro de 2005 e maio de 2006, o Portal Literal hospedou uma oficina virtual de criação poética ministrada por Carlito Azevedo. Mais do que trazer estratégias que servissem para dar gatilho à criatividade ou buscar "tornar alguém poeta", o curso teria como foco a apresentação de algumas das principais questões da produção poética na contemporaneidade. Entre elas, a discussão sobre os limites entre prosa e poesia, tema relacionado ao fazer poético do próprio Carlito Azevedo. Assim, a análise do conteúdo ministrado também permite discutir aspectos da lírica do poeta, como a presença marcante de um diálogo com outros autores e outras expressões artísticas, lida a partir dos conceitos de frequentação e escolhas afetivas.

Palavras-chave: Carlito Azevedo; oficina literária; prosa e poesia.

\section{Abstract}

Portal Literal hosted a poetry creation virtual workshop conducted by Carlito Azevedo between December 2005 and May 2006. Beyond introducing strategies that would trigger creativity or "make someone a poet", the workshop would focus on presenting some of the main issues of the contemporary poetic production, such as the discussion about the limits between prose and poetry, theme related to the poetic making of Carlito Azevedo himself. Thus, the analysis of the workshop content also allows discussing aspects of Azevedo's lyric, such as the strong presence of a dialogue with other authors and other artistic expressions, read from the concepts of frequentation and affective choices.

Keywords: Carlito Azevedo; literary workshop; prose and poetry. 